yet meticulously and rigorously dissected on its own terms, as Hamburger makes plain.

What is fascinating and puzzling about this period as seen with modern eyes is the apparently complete lack of communication between geneticists and developmental biologists. T.H. Morgan and his colleagues had laid out the basis of modern genetics by the end of the First World War, and Morgan himself was familiar with the main issues in developmental biology through working in marine stations at Naples and Woods Hole. Yet in his 766page book Experimental Embryology (1927), Morgan devoted a scant four pages to the role of chromosomes in development. Too little was known - "Whether all the genes are active all the time, or whether some of them are more active at certain stages of development than are others, are questions of profound interest". Nor was it then certain whether the chromosomes were "concerned with the making of enzymes". Morgan also devoted considerably less space to embryonic induction than he did to parthenogenesis, but that is another story. I would be curious to know whether Spemann and his school ever thought about how genes might shape the tissues, or what kind of form they imagined a complete account of embryonic induction would eventually take. Of course, in the mid-1920s there was little enough known about proteins and enzymes, let alone how genes might control their production. Given this ignorance, it is amazing how far the analysis of determination, differentiation and induction could progress, and a revelation to modern molecular eyes to see how much there is still to explain. My only regret about Hamburger's book is that it stops short of the cloning revolution, and sticks closely to amphibian development. It would be marvellous to hear his views on induction, fields and gradients in their modern dress.

1. Slack, J.M.W. From Egg to Embryo p.53 (Cambridge University Press, 1983)

2. Spemann, H. Embryonic Development and Induction pp.371-372 (Yale University Press, 1938)

Tim Hunt is a Lecturer in the Department of Biochemistry, University of Cambridge, Tennis Court Road, Cambridge CB2 1OW, UK.

\section{Condensed matter}

\section{W. R. A. Brown}

Heterochromatin: Molecular and Structural Aspects. Edited by Ram S. Verma. Cambridge University Press:1988. Pp.301. $£ 30, \$ 49.50$.

AT THE end of a eukaryotic mitosis, most of the chromatin in the cell decondenses. Some does not and remains genetically inactive - this material, with its distinctive cytological properties, is called heterochromatin.

Until recently there has been a gap between the chromosomal features that can be described with the help of a microscope and the size of DNA amenable to molecular analysis. Now, however, pulsed-field gel electrophoresis and molecular cloning in artificial yeast chromosomes are making it possible to analyse megabase pair stretches of DNA, and thus to develop molecular maps of entire eukaryotic chromosomes. These maps will include the structural information necessary for analysis of eukaryotic chromosome behaviour at a molecular level, a prospect which has brought back to prominence an older, sometimes arcane, cytogenetic literature which depicts a eukaryotic chromosome biology of extraordinary diversity. A further consequence has been the resurgence of interest in a variety of dormant cytogenetical questions, such as those surrounding the functional significance of constitutive heterochromatin.

Heterochromatin is a multi-author this is it.
The remaining six contributions can be considered in three groups. A. Lohe and $P$. Roberts review the sequence organization of satellite DNA in Drosophila melanogaster and other Drosophila species; this chapter will be of particular value to those working either on other aspects of Drosophila biology or on the satellite DNA of other organisms. The next three chapters describe aspects of our knowledge of the ultrastructure of heterochromatin. Here there is duplication and unresolved contradiction, and it would have been better to have had this interesting and apparently controversial area covered in a single authoritative article. The last two contributions describe two rather specialized aspects of human cytogenetics, the first dealing with the use of restriction endonucleases as reagents to help produce banding patterns in human chromosomes, the second with the techniques for detecting human chromosome heteromorphisms.

Altogether this is an uneven book, both in organization and in the quality of the contents. Much is omitted. The discussion of satellite DNA in Drosophila is useful, but why is there no general review of tandemly repeated, simple-sequence DNA in other organisms? The molecular basis of mammalian X-chromosome inactivation is covered only briefly. Heterochromatin in plants is mentioned only in passing. Thus the editor has failed in his goal of putting together a comprehensive account of the subject. Nevertheless John's review alone justifies publication of the book, and will ensure that it has a part in the revitalization of the study of heterochromatin.

W. R. A. Brown is in the Cancer Research Campaign Chromosome Molecular Biology Group, Department of Biochemistry, University of $O x$ ford, Oxford $O X I 3 Q U, U K$

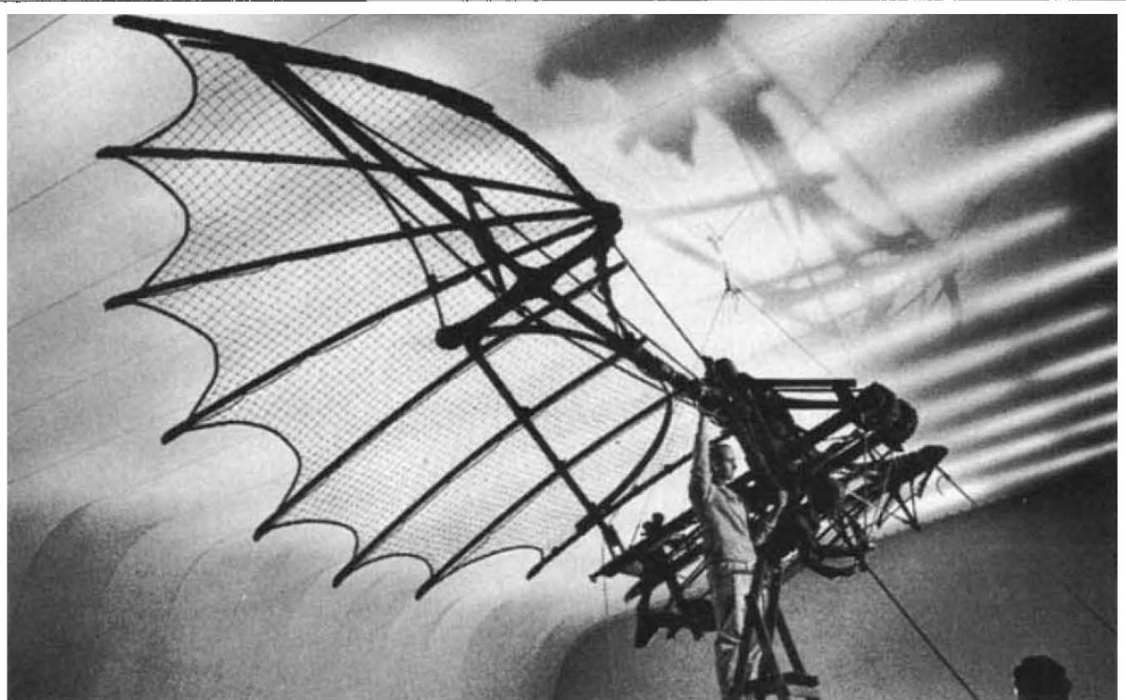

Swooping down the ages - a flying machine, made of natural materials, and based on drawings of Leonardo da Vinci. The machine features in the Leonardo exhibition which opens at the Hayward Gallery, London, today. The book-of-the-exhibition ("an invaluable guide to Leonardo's universe") is also published today by Yale University Press. 